\title{
A Novel Ski-Snow Tribometer and its Precision
}

\author{
M. Hasler ${ }^{1}$ (1) $\cdot$ K. Schindelwig ${ }^{2}$ B. Mayr ${ }^{1} \cdot$ Ch. Knoflach $^{2} \cdot$ S. Rohm $^{1} \cdot$ \\ J. van Putten ${ }^{1} \cdot$ W. Nachbauer ${ }^{1,2}$
}

Received: 16 April 2016/ Accepted: 14 July 2016/Published online: 26 July 2016

(c) The Author(s) 2016. This article is published with open access at Springerlink.com

\begin{abstract}
Friction between skis and snow was studied in a variety of field and laboratory measurements. Whilst field tests have the drawback of changing conditions, in laboratory tests sport-specific sample sizes and speeds could not be measured up to now. Hence, a novel linear tribometer was developed allowing studies with whole skis at sportspecific speeds. The precision of the tribometer was better than $2.2 \%$. The dominant cause for the imprecision was the variability of the single snow tracks at lower speed, whilst at higher speeds also the determination of normal and friction force and speed became relevant. The precision is high enough for discriminating differences needed for the analysis of different ski and snow conditions and the study of friction processes.
\end{abstract}

Keywords Ice friction - Snow - Friction test methods . Data acquisition - Hydrodynamic friction - Equipment monitoring

\section{Introduction}

The friction of skis on snow is influenced by a variety of factors, e.g. speed, contact area, snow type (temperature, liquid water content, hardness, texture) and ski properties (stiffness, thermal conductivity, base material, base roughness) [1]. The low friction on snow is caused by

M. Hasler

michael.hasler@uibk.ac.at

1 Technology Centre for Ski and Alpine Sports, 6020 Innsbruck, Austria

2 Department of Sport Science, University of Innsbruck, 6020 Innsbruck, Austria meltwater lubrication due to frictional heating [2]. In the absence of the water film, friction is supposed to be highest, and with an optimal film thickness, a minimal friction force occurs [3, 4]. The generation of frictional heat was estimated [5], modelled [6, 7] and measured [6, 8, 9]. The liquid water film was studied in laboratory $[10,11]$ and in the field [12]. Regarding the length of skis, it is very likely that friction mechanisms change along the ski base. In the region of the ski shovel, dry friction is supposed to dominate [6]. The resulting frictional heat melts the uppermost snow surface to provide lubrication for the succeeding slider sections.

Fundamental knowledge of friction on snow and ice was mainly derived from laboratory measurements. The measurement systems can be divided into two groups: linear and rotational tribometers. In the first group, probes are linearly moved on a snow or ice surface or vice versa (e.g. [13]). Speeds up to $0.5 \mathrm{~ms}^{-1}$ [14] and samples of maximum sizes of $150 \mathrm{~mm} \times 100 \mathrm{~mm}$ [13] were investigated. The second group comprises rotational systems [9, 11, 15-18]. Most of them applied the "pin-on-disc" setup, where a pin is held stationary over a rotating disc. The highest velocities with up to $20 \mathrm{~ms}^{-1}$ were reached on ice by Bäurle et al. [19]. Sample sizes on these tribometers were limited to $70 \mathrm{~mm} \times 200 \mathrm{~mm}$ [16], $100 \mathrm{~mm} \times 55 \mathrm{~mm}$ [18], $40 \mathrm{~mm} \times 40 \mathrm{~mm}$ [9] and $10 \mathrm{~mm} \times 10 \mathrm{~mm}$ [11]. The limitations of the existing tribometers are imposed by their construction. In pin-on-disc setups, discs covered with ice or snow are rotating. By the repeated contact of the probe with the snow or ice on each rotation, temperature and water film can subsequently build up and the snow surface is polished with each passage of the probe. With increasing disc velocity, centrifugal forces may alter the snow surface and the water film [18]. Due to the size limitation of the samples, friction along the ski cannot be considered. Lifelike 
velocities and the diversity of outdoor snow are additional unmet demands of tribometer experiments.

Reams of field tests with skiers on gliding tracks are carried out every year to find fast skis or ski preparations for competitions. These tests offer valuable indication on friction optimisation. Regrettably, they are impaired by changing environmental conditions and variations in the skier's motion. To determine snow friction from field tests, air and gliding resistance would have to be separated which constitutes a major problem, especially when measuring at high speeds where drag is overwhelming. In addition, the conduction of outdoor tests is time-consuming and cumbersome. As these field tests provide proprietary information for companies and national ski federations, only few measurements have been published [1, 20, 21].

The limitations of field tests as well as the limitations of the currently used laboratory devices led to the development of a novel tribometer. The purpose of this paper was to describe the novel tribometer and its measurement precision.

\section{Method}

\subsection{Tribometer}

The linear-type tribometer (Fig. 1) consists of guiding rail (c), carriage (a) and trough for snow or ice (b). The carriage runs on the guiding rail on four rollers (FR 20, Güdel AG, Switzerland). It is pulled via light fibre cables (Vectran 3000, FSE Robline, Czech Republic) by a high torque electric motor (DST2-135BO54W-150-5, Baumüller, Austria). Carriage's speed can be set between 0.1 and $30 \mathrm{~ms}^{-1}$. The runway of the carriage is $24 \mathrm{~m}$ long and is

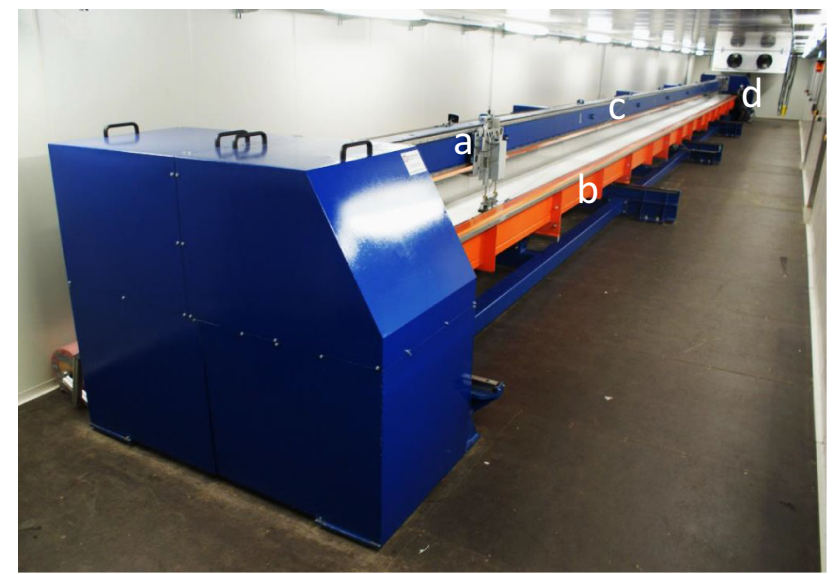

Fig. 1 Linear tribometer with carriage $(a)$, snow trough $(b)$, guiding rail $(c)$ and motor $(d)$ divided into an acceleration, measurement and deceleration section. The length of the acceleration section varies from 1 to $7 \mathrm{~m}$ depending on the measurement speed. The subsequent measurement section extends up to maximum of $18 \mathrm{~m}$, and in the last section, the carriage is stopped. Depending on speed, the carriage is decelerated by either the electric motor $\left(<20 \mathrm{~ms}^{-1}\right)$ or an eddy current brake $\left(\geq 20 \mathrm{~ms}^{-1}\right)$. The trough for snow or ice can be moved laterally in order to allow several runs on a fresh snow surface.

On the carriage (Fig. 2), two parallel vertical, springloaded (a) bars are mounted which allow the variation of the vertical force between 50 and $700 \mathrm{~N}$. The spring forces are measured by load cells (b) [S2M, $5 \mathrm{kN}$, Hottinger Baldwin Messtechnik (HBM), Austria]. At the lower end of the bars, the horizontal force measuring system is positioned. It consists of the lower carriage (d) attached to two horizontal bars by linear roll bearings. The sample is connected underneath to this lower carriage. Due to the alignment of the bars and bearings, the slide can only move horizontally and thus only the horizontal forces are transmitted to the load cell (c) (S2M, HBM, Austria), which is mounted between slide and guide of the lower carriage. The signals of all three load cells are acquired by a 24-bit full-bridge module (NI 9237, National Instruments, USA) at $8300 \mathrm{~Hz}$. Data are transmitted wirelessly (NI WLS9193, National Instruments, USA) to the control room.

The position of the carriage is measured by an inductive length measuring system. It consists of the scanning head [LMK-132.Z-0-1-6, Automatisierung Messtechnik Optik $\mathrm{GmbH}$ (AMO), Austria] mounted on the carriage and the measuring tape (LMB-130.2, AMO, Austria) fixed to the guiding rail. The resolution of the system is $3 \mathrm{~mm}$, and the accuracy is $3 \mu \mathrm{m}$. Data are acquired with a digital I/O module (NI 9402, National Instruments, USA) and

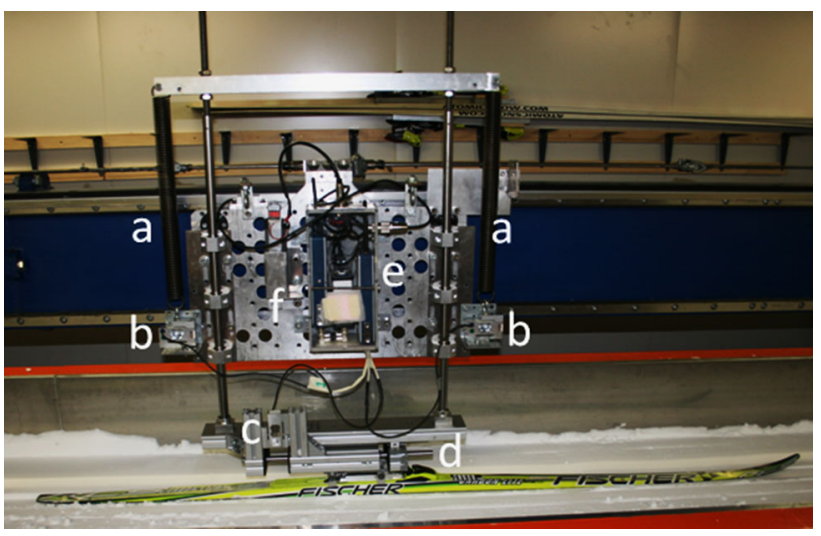

Fig. 2 Carriage with attached cross-country ski. Vertical springs (a), vertical load cells $(b)$, load cell horizontal force $(c)$, lower carriage $(d)$, data acquisition and transmission system $(e)$ and LiIon battery $(f)$ 
transmitted wirelessly (NI cDAQ-9191, National Instruments, USA) to the control room.

The tribometer is located in a cooling chamber with a lower air temperature limit of $-20{ }^{\circ} \mathrm{C}$.

\subsection{Determination of the Coefficient of Friction (CoF)}

For a single measurement run, the carriage with the mounted ski is placed on the snow surface at the start position and the vertical force is applied by loading the springs. Then, the carriage is accelerated to the target speed and passes the measurement section. After the deceleration, the carriage automatically moves back to the start at a speed of $1 \mathrm{~ms}^{-1}$. The horizontal and vertical forces are recorded for the whole run. During initial acceleration, friction force and the inertia forces of slide, boot adapter, binding and ski act on the horizontal load cell. In the subsequent measurement section, small variations of the carriage speed $v_{\mathrm{c}}$ occur due to the preceding acceleration and the elasticity of the fibre cables (Fig. 3). Horizontal and vertical forces are low-pass filtered by a Butterworth filter, cut-off frequency of $15 \mathrm{~Hz}$. The standard deviation of the filtered vertical force data was $0.7 \%$ of their arithmetic means in the measurement section.

Figure 4a shows the filtered horizontal force $F_{\mathrm{h}}$ for one measurement. In Fig. 4b, the horizontal force in the measurement section is given at higher vertical resolution.

The measured horizontal force is composed of friction force $F_{\mathrm{f}}$, inertia force $F_{\mathrm{i}}$ due to speed variations and air drag $F_{\mathrm{d}}$. The inertia force $F_{\mathrm{i}}$ is calculated by $F_{\mathrm{i}}=\left(m_{\mathrm{p}}+m_{\mathrm{cbb}}\right) a_{\mathrm{c}}$

with the mass of the probe $m_{\mathrm{p}}$, the mass of the lower carriage, boot adapter and binding $m_{\mathrm{cbb}}$, and the acceleration of the carriage $a_{\mathrm{c}}$. Carriage speed $v_{\mathrm{c}}$ and carriage acceleration $a_{\mathrm{c}}$ are determined by the first and second derivatives of the carriage position $s_{\mathrm{c}}$, respectively. Air drag $F_{\mathrm{d}}$ is calculated according to:

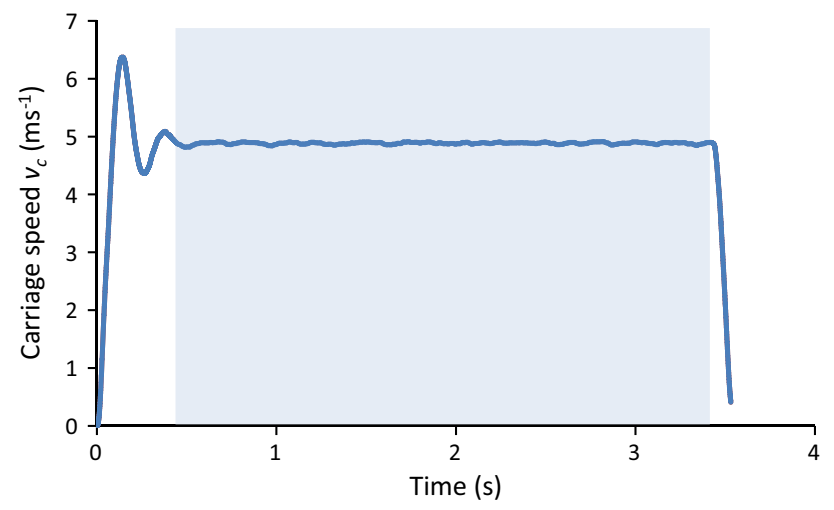

Fig. 3 Carriage speed in a run. The shaded area indicates the measurement section
$F_{\mathrm{d}}=\frac{1}{2} \rho c_{\mathrm{d}} A v_{\mathrm{c}}^{2}$.

The drag area $c_{\mathrm{d}} A$ was experimentally determined by measuring the resistance force of a flat ski without snow contact with the tribometer $c_{\mathrm{d}} A=5.15 \times 10^{-3} \mathrm{~m}^{2}$. Figure 5 shows friction force $F_{\mathrm{f}}$, inertia force $F_{\mathrm{i}}$, air drag $F_{\mathrm{d}}$ and the vertical forces $F_{\mathrm{S} 1}$ and $F_{\mathrm{S} 2}$. The strong variations of $F_{\mathrm{i}}$ are not caused by measurement noise but by real inertia forces due to small variations of the carriage speed. The variance in $F_{\mathrm{h}}$ (Fig. 4b) is mainly caused by $F_{\mathrm{i}}$ variations, and thus, the course of $F_{\mathrm{f}}$ is much smoother than one would expect from the raw measurement data.

The friction force $F_{\mathrm{f}}$ is calculated by

$F_{\mathrm{f}}=F_{\mathrm{h}}-F_{\mathrm{i}}-F_{\mathrm{d}}$.

For the measurement section (shaded area), the arithmetic mean $\overline{F_{\mathrm{f}}}$ of the friction force $F_{\mathrm{f}}$ was calculated.

The normal force $F_{\mathrm{N}}$ is given by

$F_{\mathrm{N}}=F_{\mathrm{S} 1}+F_{\mathrm{S} 2}+\left(m_{\mathrm{p}}+m_{\mathrm{msb}}\right) g$

with the vertical spring forces $F_{\mathrm{S} 1}$ and $F_{\mathrm{S} 2}$ plus the weight of the measurement system with vertical bars and binding $m_{\mathrm{msb}}$ and mass of the probe $m_{\mathrm{p}}$. For the measurement section, the arithmetic mean $\overline{F_{\mathrm{N}}}$ of the normal force $F_{\mathrm{N}}$ was calculated.

The $\operatorname{CoF}(\mu)$ is obtained by

$\mu=\overline{F_{\mathrm{f}}} / \overline{F_{\mathrm{N}}}$.

\subsection{Precision Measurements}

\subsubsection{Snow Surface Preparation}

The snow was produced in a dedicated cooling chamber. A mixture of water $\left(T=1^{\circ} \mathrm{C}\right)$ and air generated by an electric water pump ( $p=5.5$ bar) and an air compressor ( $p=4.2$ bar) was sprayed into the air through two nozzles (inner diameter $1.8 \mathrm{~mm}$, Sufag, Austria). The snow was produced batchwise at an air temperature between -18 and $-15{ }^{\circ} \mathrm{C}$. The snow surface was prepared in the $24-\mathrm{m}$-long, $0.8-\mathrm{m}$-wide and 0.28 -m-deep trough. It was sieved, distributed manually and then levelled evenly with a stainless steel blade fixed to a trolley that rolls on rails on both sides of the trough. Overnight the snow sintered at test conditions and hence snow hardness increased. Cooling coils positioned at the bottom of the trough were used to control snow temperature. The snow conditions were kept constant during the tests: snow temperature $-5.1 \pm 0.5^{\circ} \mathrm{C}$, snow density $486 \pm 17 \mathrm{~kg} \mathrm{~m}^{-3}$, diameter of the snow grains $0.18 \pm 0.1 \mathrm{~mm}$ and free water content of $17 \pm 3 \%$ (determined by a snow moisture metre Hygro 011, Doser Messtechnik, Kempten, Germany). 

horizontal force with higher force resolution (b) of one run. The shaded areas indicate the measurement section
Fig. 4 Horizontal force (a) and
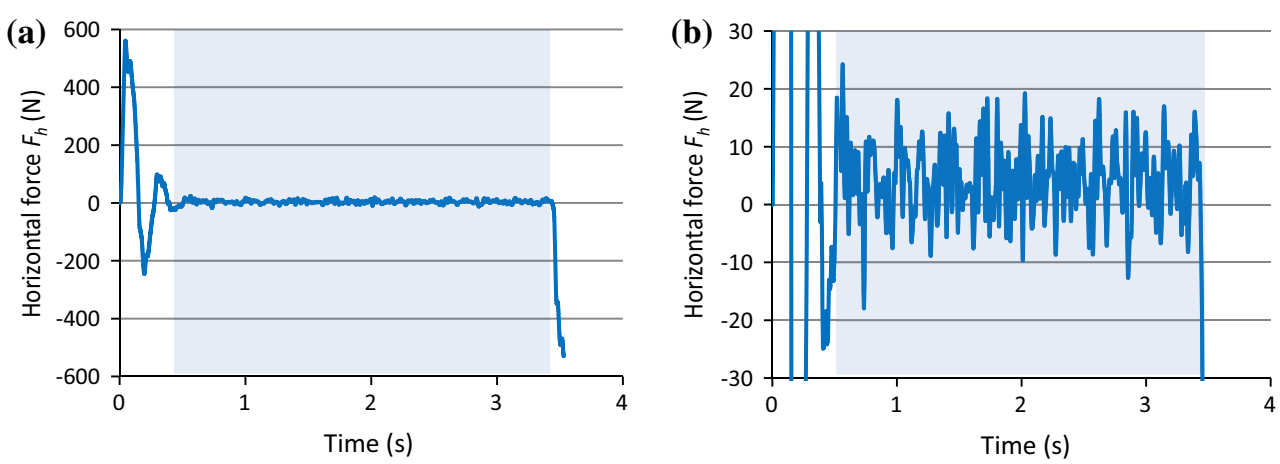

Fig. 5 Friction force (top left), inertia force (top right), air drag (lower left) and vertical spring forces $\left[F_{\mathrm{S} 1}\left(\right.\right.$ dark) and $F_{\mathrm{S} 2}$ (light), lower right] of one measurement. The shaded areas indicate the measurement section. All curves except air drag are filtered signals
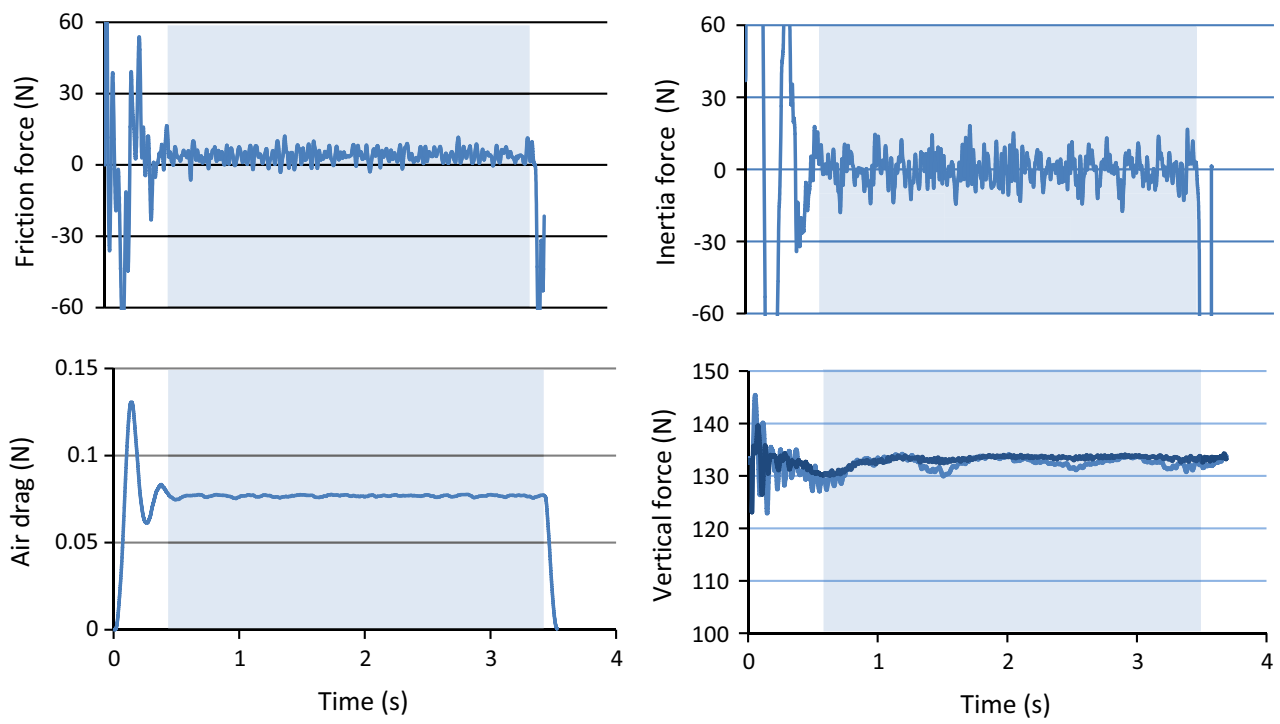

\subsubsection{Ski Surface Preparation}

A cross-country skating ski (RCS cold, $192 \mathrm{~cm}$, Fischer, Austria) was used for all tests. The base was prepared by stone grinding. Roughness profiles of the ski base surface were measured before the measurements using a $3 \mathrm{D}$ focus variation microscope (InfiniteFocus G4, Alicona Imaging, Austria). The profiles were determined for six randomly chosen lines perpendicular to the ski running direction. Roughness parameters arithmetical mean roughness $R_{\mathrm{a}}$, mean roughness depth $R_{z}$, and maximum height roughness $R_{\max }$ were calculated according to DIN EN ISO 4287 (Table 1). The ski was waxed with a common training wax (HWK K1, HWK-Kronbichler GmbH, Austria) and brushed before each measurement series.

\subsubsection{Measurement Series}

The analysis of the overall precision of the tribometer is divided into two parts: effects of variations of different snow tracks and of skis despite the same preparation on the precision and effects of the precision of the force-
Table 1 Roughness parameters of the ski base

\begin{tabular}{lll}
\hline & Roughness $(\mu \mathrm{m})$ & Standard deviation $\sigma(\mu \mathrm{m})$ \\
\hline$R_{\mathrm{a}}$ & 6.1 & 0.3 \\
$R_{z}$ & 25.8 & 0.9 \\
$R_{\max }$ & 29.5 & 1.3 \\
\hline
\end{tabular}

displacement measurement unit. This precision is only affected by the measurement errors of the load cells and the position sensor and by the measurement arrangement. The surfaces of ski and snow gradually change during a measurement series due to a variety of mechanisms as abrasion or friction melting of the snow surface. To account for these circumstances, a single measurement series consisted of 50 consecutive runs on the same snow track. First, five such test series were carried out at constant speed on different snow tracks. Each series consisting of 50 consecutive runs started on a fresh snow track. For all series, speed was set to $6 \mathrm{~ms}^{-1}$ and vertical force to $400 \mathrm{~N}$. In the initial runs from 1 to 10 , the CoF varied strongly and hence only 
the runs from 11 to 50 were analysed. To account for the successive alteration of ski and snow surface, the measured $\mathrm{CoF}$ of the runs $11-50$ was first approximated by least square polynomial fits of first to fourth order. The $\mathrm{CoF}$ varied by less than $2 \%$ between the different fits, and thus, finally the least square line was chosen. Under the assumption that the least square fit describes the effect of altering surfaces of ski and snow, the difference between the values of the linear fit and the measured values is supposed to be independent of the change in the surfaces and thus is attributed to the force-displacement measurement unit.

In a second step, series of 50 consecutive runs were conducted at the speeds of 2, 4, 6, 8 and $10 \mathrm{~ms}^{-1}$ at otherwise same conditions as in the first measurements. Each series started on a fresh snow track. The trend of the $\mathrm{CoF}$ from runs 11 to 50 was approximated by a least square line.

\subsubsection{Precision of the Tribometer}

For every run $i$ of the runs $11-50$, standard deviation $\sigma_{i}$ and relative standard deviation $\varepsilon_{i}$ of the five measurement series on different snow tracks under unvaried conditions were determined. The standard deviation $\sigma_{i}$ was calculated from the five $\mathrm{CoF}$ values $\mu_{j, i}(j=1-5)$ of the run $i$ and the arithmetic mean of these five values $\bar{\mu}_{i}$ with

$\sigma_{i}=\sqrt{\frac{1}{5} \sum_{j=1}^{5}\left(\mu_{j, i}-\bar{\mu}_{i}\right)^{2}}$

The relative standard deviation $\varepsilon_{i}$ was calculated by $\varepsilon_{i}=\sigma_{i} / \overline{\mu_{i}}$. Standard deviations $\sigma_{i}$ and relative standard deviations $\varepsilon_{i}$ were taken as measure for the overall precision of the tribometer.

\subsubsection{Precision of the Force-Displacement Measurement Unit}

To determine the effect of the precision of the force-displacement measurement unit on the tribometer precision, the differences of measured values and the associated least square line of one series were analysed. $\sigma_{\mathrm{mu}}$ of one series is calculated by

$\sigma_{\mathrm{mu}}=\sqrt{\sum_{i=11}^{50} \frac{1}{40}\left(\mu_{i}-\mu_{i \mathrm{fit}}\right)^{2}}$

where $\mu_{i}$ is the CoF of the $i$ th run and $\mu_{i}$ fit is the value of the associated least square line of the same $i$ th run.

For the relative standard deviation $\varepsilon_{\mathrm{mu}}$, the standard deviation $\sigma_{\mathrm{mu}}$ was related to the arithmetic mean $\bar{\mu}$ of the $\mathrm{CoF}$ of runs 11-50. Standard deviations $\sigma_{\mathrm{mu}}$ and relative standard deviations $\varepsilon_{\mathrm{mu}}$ were taken as measure for the precision of the force-displacement measurement unit.

\subsubsection{Effect of Snow and Ski Surface on the Precision}

To assess the influence of variations of the snow and ski surface $\varepsilon_{\mathrm{ss}}$ on the $\mathrm{CoF}$ precision despite the same preparation, only variations of the least square lines obtained at $6 \mathrm{~ms}^{-1}$ and thus without the effects of the force-displacement unit were considered. The standard deviation between the single least square lines was determined with the standard deviation $\sigma_{\mathrm{ss}, i}$ of the values of the five lines for every run.

$\sigma_{\mathrm{ss}, i}=\sqrt{\sum_{j=1}^{5} \frac{1}{5}\left(\mu_{j, i}-\bar{\mu}_{i \mathrm{fit}}\right)^{2}}$

where $\mu_{j, i}$ is the CoF value of the $i$ th run of the regression line of the $j$ th measurement series and $\bar{\mu}_{i \text { fit }}$ is the average $\mathrm{CoF}$ value of the $i$ th run of all five regression lines.

For the relative standard deviation $\varepsilon_{\mathrm{ss}, i}$, the standard deviation $\sigma_{\mathrm{ss}, i}$ was related to the arithmetic mean of the $\mathrm{CoF}$ of the single least square lines for each single run $i\left(\bar{\mu}_{i \mathrm{fit}}\right)$. The relative standard deviation $\varepsilon_{\mathrm{ss}, i}$ was taken as measure for the measurement precision influence of the different snow tracks and ski surfaces.

\section{Results}

\subsection{Measurement Series}

In Fig. 6, the CoF progressions of 50 consecutive runs on five different snow tracks are presented. All series started with low $\mathrm{CoF}$ and increased up to runs 8-11. Subsequently, the $\mathrm{CoF}$ decreased gradually. In the run-in phase, the trend of the series was not uniform and became linear after run 10.

Figure 7 shows five progressions of the $\mathrm{CoF}$ of 50 consecutive runs on the same snow track with least square lines from runs 11 to 50 at the tested speeds of 2, 4, 6, 8 and $10 \mathrm{~ms}^{-1}$. During the first 10 runs, there was a considerable change in the CoF especially at higher speeds. In the following runs, the $\mathrm{CoF}$ stayed constant at the lower speeds of 2 and $4 \mathrm{~ms}^{-1}$ and showed an increasing negative trend with increasing speeds.

\subsection{Precision of the Tribometer}

Figure 8 shows the relative standard deviations of the measured $\mathrm{CoF}$ and those calculated from the least square lines between the five series for the runs 11-50. During the test series, the relative standard deviations of the measured 


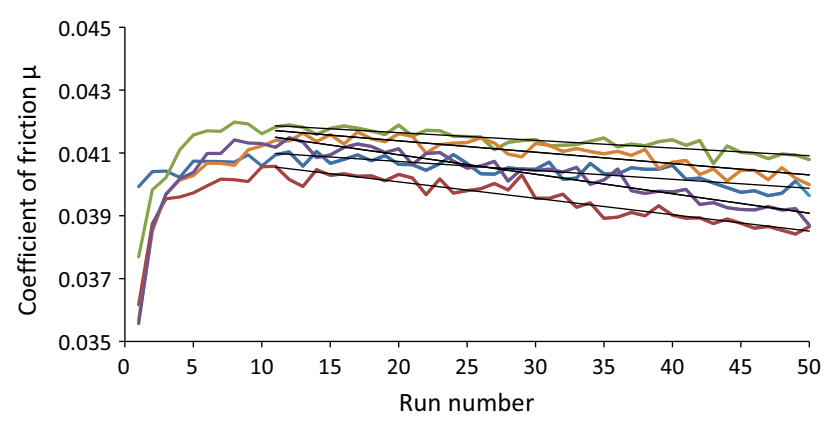

Fig. $6 \mathrm{CoF}$ progression of five measurement series of 50 consecutive runs on different snow tracks with linear regression lines from runs 11 to 50 . The carriage speed was $6 \mathrm{~ms}^{-1}$

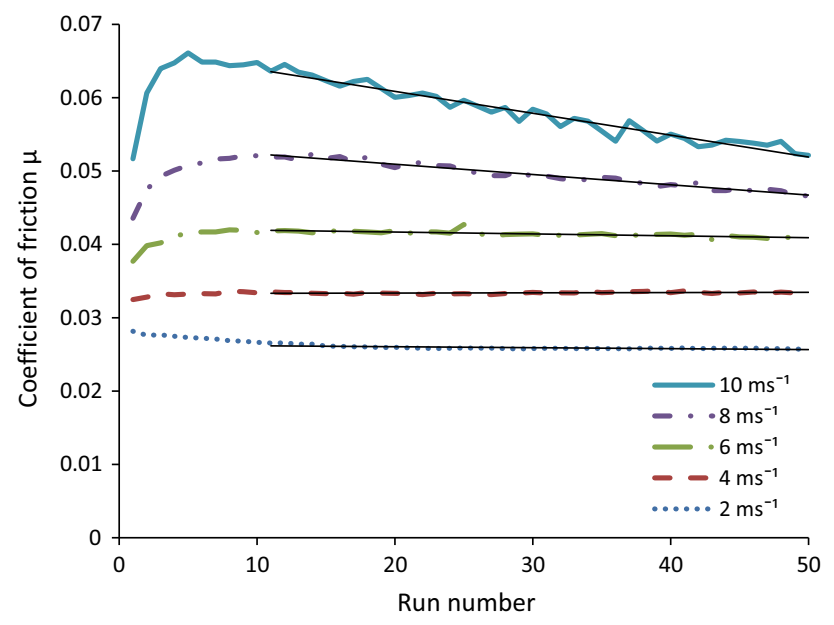

Fig. 7 Progression of the $\mathrm{CoF}$ of 50 consecutive runs on the same snow track with least square lines from runs 11 to 50 at different speeds

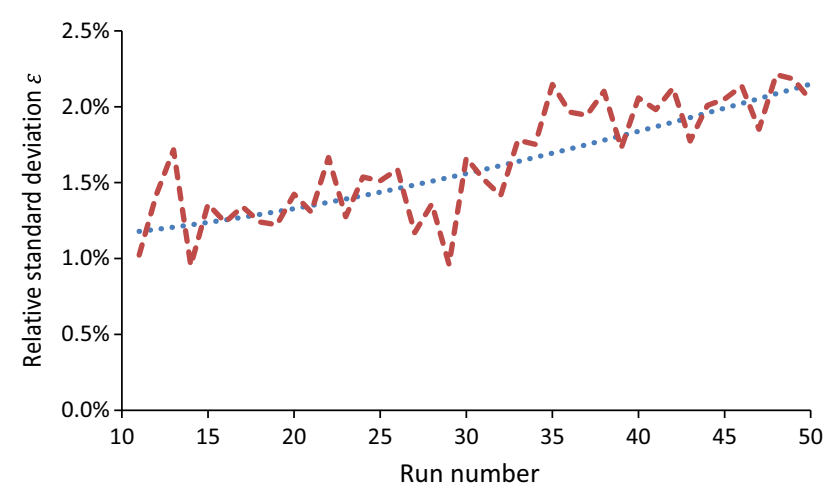

Fig. 8 Relative standard deviations $\varepsilon_{i}$ of the measured $\mathrm{CoF}$ (dashed line) and calculated from the least square lines $\varepsilon_{\mathrm{ss}, i}$ (dotted line)

$\mathrm{CoF} \varepsilon_{i}$ were between 0.95 and $2.2 \%$ and showed an increasing trend. The average of the runs 11-30 was $1.35 \%$.

\subsection{Precision of the Force-Displacement Measurement Unit}

In Table 2, standard deviations $\sigma$ and relative standard deviations $\varepsilon$ of the differences between the measured $\mathrm{CoF}$ and the least square fit of the $\mathrm{CoF}$ are given. With the exception of the lowest speed of $2 \mathrm{~ms}^{-1}$, the relative standard deviation increased with increasing speed from $0.35 \%$ at $4 \mathrm{~ms}^{-1}$ to $1.24 \%$ at $10 \mathrm{~ms}^{-1}$ (Table 2). The given standard and relative standard deviations correspond to $\sigma_{\mathrm{mu}}$ and $\varepsilon_{\mathrm{mu}}$.

\subsection{Effect of Snow and Ski Surface on the Precision}

The relative standard deviations of the least square lines $\varepsilon_{\mathrm{ss}, i}$ (Fig. 8, dotted line) increased linearly from 1.2 to $2.15 \%$ during the test series and were only slightly lower than the $\varepsilon_{\mathrm{ss}}$ (Fig. 8, dashed line).

\section{Discussion}

A novel tribometer was developed which allows snow friction measurements of whole skis under ski specific load and speed conditions. In this study, the tribometer was described in detail, and its precision was determined. Differences between measured values and their true values are denoted by accuracy. True values are usually approximated by established measurement devices with high accuracy (reference measurement). Since for snow friction no reference measurement is available, the dispersion of the $\mathrm{CoF}$ was determined in repeated measurements. This dispersion is in general referred to as precision or also repeatability.

During multiple runs on the same track, the snow surface is subject to abrasion, melting and refreezing of water. The effective contact area between ski and snow was found to increase to nearly $50 \%$ after several ski passes on the same track [22]. Changes in the size of the contact area and roughness of the contacting snow surface affect friction $[3,7]$. To account for progressive changes in the surface, the measurements were taken in series of 50 consecutive runs on the same snow track. Since there were strong variations of the $\mathrm{CoF}$ during the first 10 repetitions likely due to changes in the snow surface, precision was calculated for the runs 11-50. The relative standard deviations (RSD) for each run from 11 to 50 of the five measurement series were taken as measure for the overall precision of the tribometer. The overall precision was between 0.9 and $2.2 \%$ at the measured speed of $6 \mathrm{~ms}^{-1}$ tending to increase with increasing run number. The average RSD of the first 20 runs after the run-in was $1.35 \%$. These results suggest that after an initial run-in of 10 repetitions a series of 20 consecutive runs provides acceptable precision. The 
Table 2 Standard deviation $\sigma$ and relative standard deviation $\varepsilon$ of the differences between measured CoF and least square fit of CoF

\begin{tabular}{llllll}
\hline Speed $\left(\mathrm{ms}^{-1}\right)$ & 2 & 4 & 6 & 8 & 10 \\
\hline$\sigma$ & $1.46 \times 10^{-4}$ & $1.18 \times 10^{-4}$ & $1.94 \times 10^{-4}$ & $3.35 \times 10^{-4}$ & $7.57 \times 10^{-4}$ \\
$\varepsilon(\%)$ & 0.56 & 0.35 & 0.47 & 0.66 & 1.24 \\
\hline
\end{tabular}

accomplished precision is sufficient to discriminate differences due to different ski bases, waxes or snow conditions and to study friction mechanisms.

The overall precision of the tribometer was subdivided into effects due to variations of snow and ski and the precision of the force-speed measurement unit. Since the progressive change in the snow surface is a continuous and smooth process, the precision of the force-speed measurement was expressed by the deviations between measured $\mathrm{CoF}$ and their least square fit. Five different measurement speeds were analysed. The precision of the measurement unit was speed dependent with an increase from $0.35 \%$ at $4 \mathrm{~ms}^{-1}$ to $1.24 \%$ at $10 \mathrm{~ms}^{-1}$. Causes for the speed dependency are as follows. With increasing speed, the acceleration section on the tribometer increases causing the measurement section to shorten. Moreover, due to the higher speed the time for passing the measurement section is reduced. These result in measurement times of $7.4 \mathrm{~s}$ at $2 \mathrm{~ms}^{-1}$ and $1.1 \mathrm{~s}$ at $10 \mathrm{~m}^{-1}$. Averages over longer measurement times enhance the filtering of noise and acceleration-induced vibrations. The carriage is subject to high forces especially when measuring at high speeds. These forces generate vibrations and deformations of the measuring components and thus errors in the measurements. The carriage speed is used for calculating the inertia force of the sample plus binding, which is a component of the measured horizontal force. Errors in the measurement of forces and the calculation of the inertia force directly affect the CoF.

Changes in the contacting surfaces caused by the repeated runs on the same track were approximated by least square fits of the CoF. The least square lines of five measurement series on different snow tracks at a speed of $6 \mathrm{~ms}^{-1}$ were compared in order to assess the effect of different snow tracks and ski surface variations on precision. From run 11 to run 50, the RSD strictly increased from 1.18 to $2.15 \%$ at the analysed speed of $6 \mathrm{~ms}^{-1}$. These deviations must be caused by differences between the five snow tracks and the ski waxing. Despite intense efforts to standardise snow production and preparation of the snow runway, the snow surface likely was not completely homogeneous. Skis were waxed in a standardised way; however, small differences in the preparation may have occurred. The increase in the RSD with increasing repetitions suggests that the inhomogeneity of the snow surface tends to get larger with ongoing wear. At the speed of $6 \mathrm{~ms}^{-1}$, the effect of differences between the snow tracks and ski preparation of $2.15 \%$ accounted for the major part of the overall precision which was determined with $2.2 \%$.

The conducted experiments revealed that the contacting surfaces are continuously subjected to alterations during friction measurements. There was almost no change in the $\mathrm{CoF}$ with increasing run number at speeds below $6 \mathrm{~ms}^{-1}$. At the higher speeds of 6,8 and $10 \mathrm{~ms}^{-1}$, the $\mathrm{CoF}$ decreased with increasing run number whilst the decrease increased with increasing speed. This may be attributed to the increasing friction power with increasing speed. At lower speeds, the heat generated by the friction process may not be sufficient for a substantial change in the snow surface. With increasing friction power, the surfaces are continuously modified by frictional melting causing the $\mathrm{CoF}$ to drop. The linear decrease from runs 11 to $50 \mathrm{sug}$ gests that the final state of the surface modification was not yet reached.

Friction increased with increasing speed which is in agreement with other measurements at similar snow conditions [23, 24]. Figure 8 shows the $\mathrm{CoF}$ as function of the speed for the runs 11 and 50. Whilst at run 11 the relation is linear, the last run is best approximated by the exponential function: $\mu=0.0186 v^{0.44}$. Table 3 shows the coefficients of determination $\left(R^{2}\right)$ of the linear and the exponential fit and the coefficients with standard errors (SE).

Oksanen et al. [25] on ice found a speed dependence of the CoF proportional to $v^{0.5}$ at $-1{ }^{\circ} \mathrm{C}$. This suggests that, due to wear by the repeatedly passing ski, the snow surface gets more and more polished and hence similar to an ice surface. The wear and polishing effect is most pronounced at the higher speeds of $6 \mathrm{~ms}^{-1}$ and beyond (Fig. 9).

Concluding it can be stated that the linear tribometer is a precise tool to analyse friction on snow or ice with sportspecific samples and speeds. The dominant cause for the imprecision at lower speed is the variability of the snow tracks, whilst at higher speeds also the measurements of forces and speed become relevant. The precision is high enough for discriminating differences needed for the assessment of different ski and snow conditions and the study of friction processes. For an understanding of the underlying mechanisms, nonetheless additional data such as the thickness of the water film or the temperatures of the 
Table 3 Coefficient of determination $\left(R^{2}\right)$ of the fits of run 11 and run 50 and coefficients with standard error (SE)

\begin{tabular}{llllll}
\hline & $R^{2}$ & $a$ & SE $a$ & $b$ & SE $b$ \\
\hline Run $11 \mu=a v+b$ & 0.99 & $4.7 \mathrm{E}-3$ & $2.5 \mathrm{E}-4$ & $1.53 \mathrm{E}-2$ & $1.7 \mathrm{E}-3$ \\
Run $50 \mu=a v^{\mathrm{b}}$ & 0.99 & $1.87 \mathrm{E}-2$ & $4.6 \mathrm{E}-4$ & $4.4 \mathrm{E}-1$ & $1.4 \mathrm{E}-2$ \\
\hline
\end{tabular}

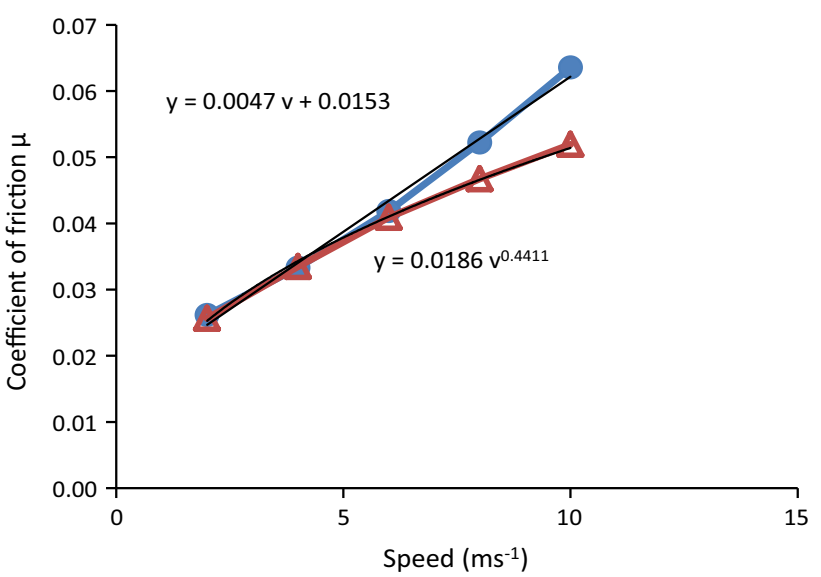

Fig. 9 Friction coefficient $\mu$ versus speed of run 11 (full circles) and run 50 (open triangles) with trend lines

materials and simulations regarding thermodynamics, fluid dynamics and characterisation of the surfaces will be necessary.

Acknowledgments Open access funding provided by University of Innsbruck and Medical University of Innsbruck. This research was funded by the project "K-Regio: Skitechnologie" of the Land Tirol.

Open Access This article is distributed under the terms of the Creative Commons Attribution 4.0 International License (http://crea tivecommons.org/licenses/by/4.0/), which permits unrestricted use, distribution, and reproduction in any medium, provided you give appropriate credit to the original author(s) and the source, provide a link to the Creative Commons license, and indicate if changes were made.

\section{References}

1. Nachbauer, W., Schröcksnadel, P., Lackinger, B.: Effects of snow and air conditions on ski friction. In: Mote, C.D., Johnson, J.R.J., Hauser, W., Schaff, P.S. (eds.) Skiing trauma and safety, vol. 10, pp. 178-185. American Society for Testing and Materials, West Conshohocken (1996)

2. Bowden, F.P., Hughes, T.P.: The mechanism of sliding on ice and snow. In: Proceedings of the Royal Society of London Series A, Mathematical and Physical Sciences, vol. 172(A949), pp. 280-298 (1939). doi:10.1098/rspa.1939.0104

3. Colbeck, S.C.: The kinetic friction of snow. J. Glaciol. 34(116), 78-86 (1988)

4. Colbeck, S.C.: A review of the friction of snow skis. J. Sports Sci. 12(3), 285-295 (1994)

5. Bowden, F.P., Tabor, D.: The area of contact between stationary and between moving surfaces. In: Proceedings of the Royal
Society of London. Series A, Mathematical and Physical Sciences, vol. 169(938), pp. 391-413 (1939)

6. Evans, D.C.B., Nye, J.F., Cheeseman, K.J.: The kinetic friction of ice. In: Proceedings of the Royal Society of London. A. Mathematical and Physical Sciences, vol. 347(1651), pp. 493-512 (1976). doi:10.1098/rspa.1976.0013

7. Bäurle, L., Kaempfer, T.U., Szabó, D., Spencer, N.D.: Sliding friction of polyethylene on snow and ice: contact area and modeling. Cold Reg. Sci. Technol. 47(3), 276-289 (2007). doi:10.1016/j.coldregions.2006.10.005

8. Liang, H., Martin, J.M., Mogne, T.L.: Experimental investigation of friction on low-temperature ice. Acta Mater. 51(9), 2639-2646 (2003). doi:10.1016/s1359-6454(03)00061-2

9. Bäurle, L., Szabo, D., Fauve, M., Rhyner, H., Spencer, N.D.: Sliding friction of polyethylene on ice: tribometer measurements. Tribol. Lett. 24(1), 8 (2006). doi:10.1007/s11249-006-9147-z

10. Petrenko, V.F.: The effect of static electric fields on ice friction. J. Appl. Phys. 76(2), 1216-1219 (1994)

11. Strausky, H., Krenn, J.R., Leitner, A., Aussenegg, F.R.: Sliding plastics on ice: fluorescence spectroscopic studies on interfacial water layers in the $\mu \mathrm{m}$ thickness regime. App. Phys. B Lasers Opt. 66(5), 599-602 (1998). doi:10.1007/s003400050442

12. Ambach, W., Mayr, B.: Ski gliding and water film. Cold Reg. Sci. Technol. 5(1), 59-65 (1981). doi:10.1016/0165-232x(81)90040-9

13. Jones, S.J., Kitagawa, H., Izumiyama, K., Shimoda, H.: Friction of melting ice. Ann. Glaciol. 19, 7-12 (1994)

14. Montagnat, M., Schulson, E.M.: On friction and surface cracking during sliding of ice on ice. J. Glaciol. 49(166), 391-396 (2003)

15. Dumm, M., Hainzlmaier, C., Boerboom, S., Wintermantel, E.: The effect of pressure on friction of steel and ice and implementation to bobsleigh runners. In: Moritz, E., Haake, S. (eds.) The Engineering of Sport 6, pp. 103-106. Springer, New York (2006)

16. Fauve, M., Bäurle, L., Rhyner, H.: Laboratory device for measuring the friction between ski-base materials and ice or snow. In: Moritz, E., Haake, S. (eds.) The Engineering of Sport 6, pp. 251-256. Springer, New York (2006)

17. Kietzig, A.-M., Hatzikiriakos, S.G., Englezos, P.: Ice friction: the effects of surface roughness, structure, and hydrophobicity. J. Appl. Phys. 106(2), 024303-024310 (2009). doi:10.1063/1.3173346

18. Takeda, M., Nikki, K., Nishizuka, T., Abe, O.: Friction of the short model ski at low velocity. J. Phys. Conf. Ser. 258(1), 012007 (2010)

19. Bäurle, L., Szabó, D., Fauve, M., Rhyner, H., Spencer, N.D.: Sliding friction of polyethylene on ice: tribometer measurements. Tribol. Lett. 24(1), 77-84 (2006). doi:10.1007/s11249-006-9147-z

20. Leino, M.A.H., Spring, E., Suominen, H.: Methods for the simultaneous determination of air resistance to a skier and the coefficient of friction of his skis on the snow. Wear 86(1), 101-104 (1983). doi:10.1016/0043-1648(83)90092-3

21. Erkkilä, J.: A cinematographic method for determination of the kinetic friction of skis on snow. Department of Geophysics, University of Helsinki, Helsinki (1985)

22. Colbeck, S.C.: A review of the processes that control snow friction. US Army Cold Regions Research and Engineering Laboratory Monograph 92-2 (1992) 
23. Nachbauer, W., Kaps, P., Hasler, M., Mössner, M.: Friction between ski and snow. In: Braghin, F., Cheli, F., Maldifassi, S., Melzi, S., Sabbioni, E. (eds.) The Engineering Approach to Winter Sports, pp. 17-32. Springer, New York (2016)
24. Kuroiwa, D.: The kinetic friction on snow and ice. J. Glaciol. 19(81), 141-152 (1977)

25. Oksanen, P., Keinonen, J.: The mechanism of friction on ice. Wear 78(3), 315-324 (1982) 